Supporting Information

\title{
NMR Spectroscopic Studies Reveal the Critical Role of Isopeptide Bond in Forming the Otherwise Unstable SpyTag-SpyCatcher Mutant Complexes
}

Nan Zhang ${ }^{\S, 1,2}$, Jing Liu ${ }^{\S, 1,3}$, Yajie Liu ${ }^{1,2}$, Wen-Hao Wu ${ }^{1,2}$, Jing Fang ${ }^{1,2}$, Xiao-Di Da ${ }^{1,2}$, Shenlin Wang ${ }^{* 1,3}$, Wen-Bin Zhang ${ }^{* 1,2}$

${ }^{1}$ Beijing National Laboratory for Molecular Sciences, College of Chemistry and Molecular Engineering, Peking University, Beijing 100871, P. R. China

${ }^{2}$ Key Laboratory of Polymer Chemistry \& Physics of Ministry of Education, Center for Soft Matter Science and Engineering, Peking University, Beijing 100871, P. R. China

${ }^{3}$ Beijing NMR Center, Peking University, Beijing 100871, P. R. China

$\S$ These authors contributed equally to the work. 


\section{Experimental Section}

Protein Characterization. Sodium dodecyl sulfate polyacrylamide gel electrophoresis (SDS-PAGE) was performed on $10 \%$ gels to analyze the samples and the reactions. Samples were mixed with 5x SDSPAGE loading buffer (250 mM Tris-HCl, 50\% glycerol, 10\% SDS, $250 \mathrm{mM} \beta$-mercaptoethanol, 0.05\% bromophenol blue) and heated at $98^{\circ} \mathrm{C}$ for $10 \mathrm{~min}$ before loading. Size exclusion chromatography was performed on a Superdex 200 Increase 10/300 GL column in an ÄKTA FPLC system (GE Healthcare, Inc.) using PBS ( $\mathrm{pH}=7.4)$ as the mobile phase at a flow rate of $0.5 \mathrm{~mL} / \mathrm{min}$. Matrix assisted laser desorption ionization time-of-flight mass spectrometer (MALDI-TOF MS) was conducted on a MALDI TOF/TOF 5800 mass spectrometer (AB Sciex, USA) with sinapinic acid as the matrix.

Circular Dichroism Spectroscopy. The proteins and peptides were dissolved in PBS buffer $(\mathrm{pH}=$ 7.4). The concentration of all the proteins for CD experiments was $\sim 1 \mathrm{mg} / \mathrm{mL}$. The peptide solution was added into the protein samples with a molar ratio of $2: 1$ and incubated at $4{ }^{\circ} \mathrm{C}$ for 12 hours to get the peptide-protein complexes or mixtures. The mixture of SpyCatcher and SpyTagw was incubated at $37{ }^{\circ} \mathrm{C}$ for 12 hours to get the covalent complex. All the far-UV CD spectra were obtained on a Chirascan-plus CD spectrometer (Applied Photophysics Ltd., United Kingdom) at $25{ }^{\circ} \mathrm{C}$. Samples were scanned every 1 $\mathrm{nm}$ with a 2-nm bandwidth from $190 \mathrm{~nm}$ to $260 \mathrm{~nm}$ using a quartz cuvette with a path length of $0.1 \mathrm{~mm}$ for 2 repeats. The collection time per point was set as $0.5 \mathrm{~s}$. All scans were repeated twice.

LC-MS Spectroscopy. The protein samples and protein-peptide mixtures in PBS were changed into $\mathrm{ddH}_{2} \mathrm{O}$ by ultrafiltration and the concentrations were $1-2 \mathrm{mg} / \mathrm{mL}$. Ultra-performance liquid chromatography-electrospray ionization mass spectrometry (UPLC-ESIMS) analyses were performed on a system equipped with an ACQUITY H-Class UPLC (Waters Corp.) and a quadrupole rods SQ Detector 2 mass spectrometer (Waters Corp.). A protein BEH C4 column (Waters $300 \AA ̊ .1 .7 \mu \mathrm{m} ; 2.1 \times 50 \mathrm{~mm}$ ) was used for separation with ultrapure water (with $0.1 \%$ formic acid) and acetonitrile as the mobile phase. 
Amino Acid Sequence and Molecular Weight Information for SpyCatcher Variants

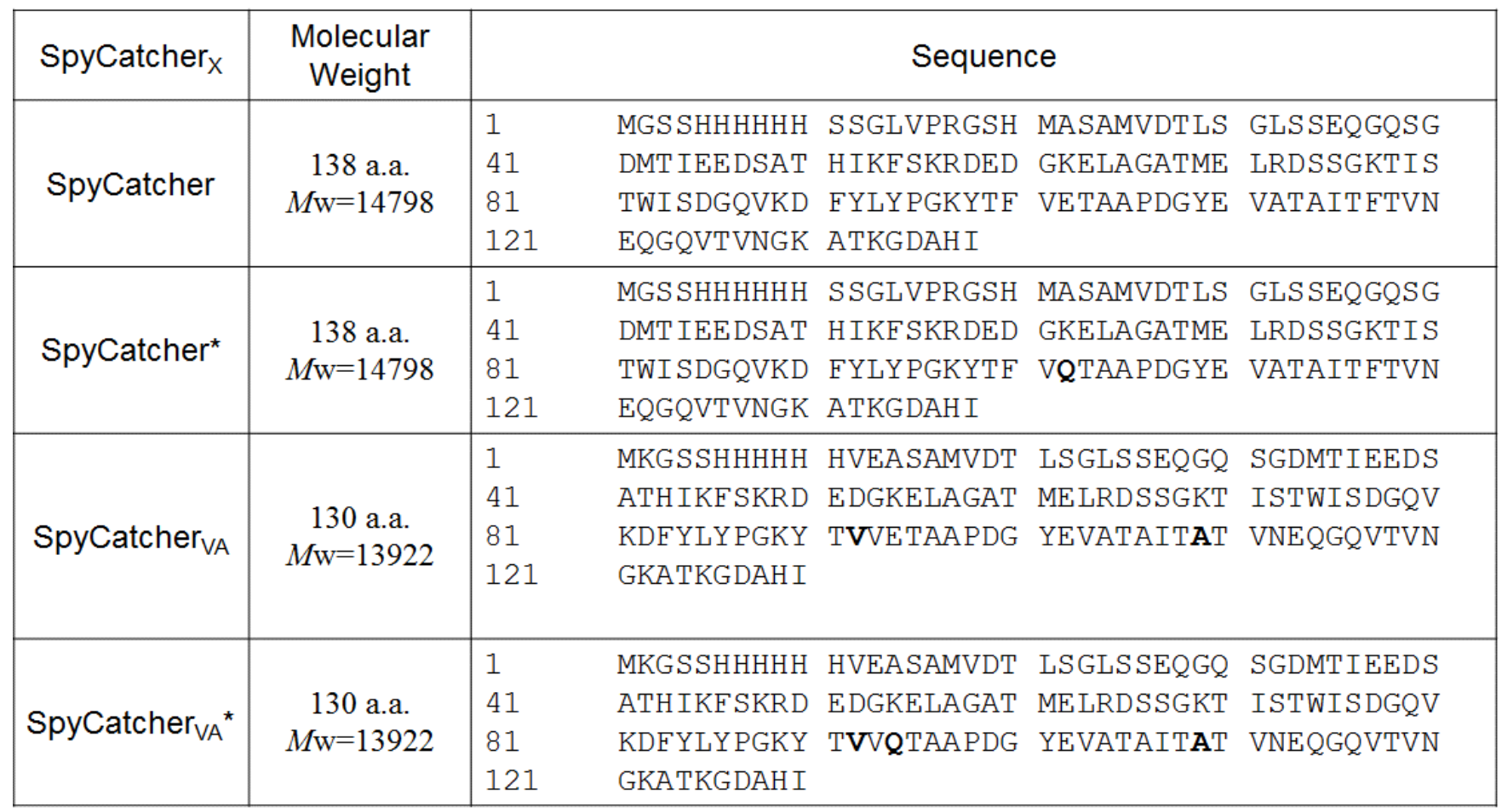

Amino Acid Sequence and Molecular Weight Information for SpyTag Variants

\begin{tabular}{|c|c|c|}
\hline SpyTag $_{\mathrm{x}}$ & Molecular Weight & Sequence \\
\hline SpyTag & 16 a.a. $M \mathrm{w}=1704$ & AHIVMVDAYKPTKGSS \\
\hline SpyTag $_{\mathrm{Y}}$ & 16 a.a. $M \mathrm{w}=1754$ & AHYVMVDAYKPTKGSS \\
\hline SpyTag $_{\mathrm{W}}$ & 16 a.a. $M \mathrm{w}=1777$ & AHWVMVDAYKPTKGSS \\
\hline
\end{tabular}


Amino Acid Sequence and Molecular Weight Information for SUMO-SpyTagx Proteins

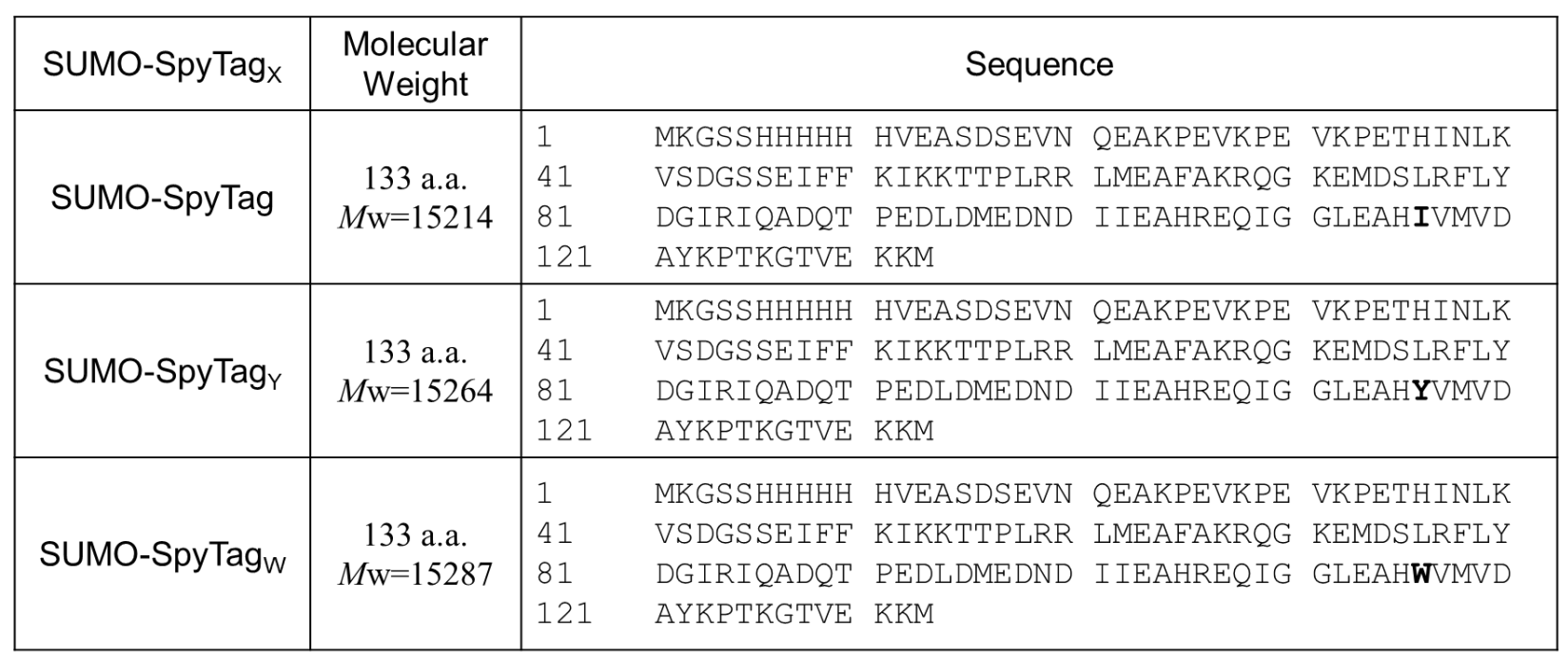




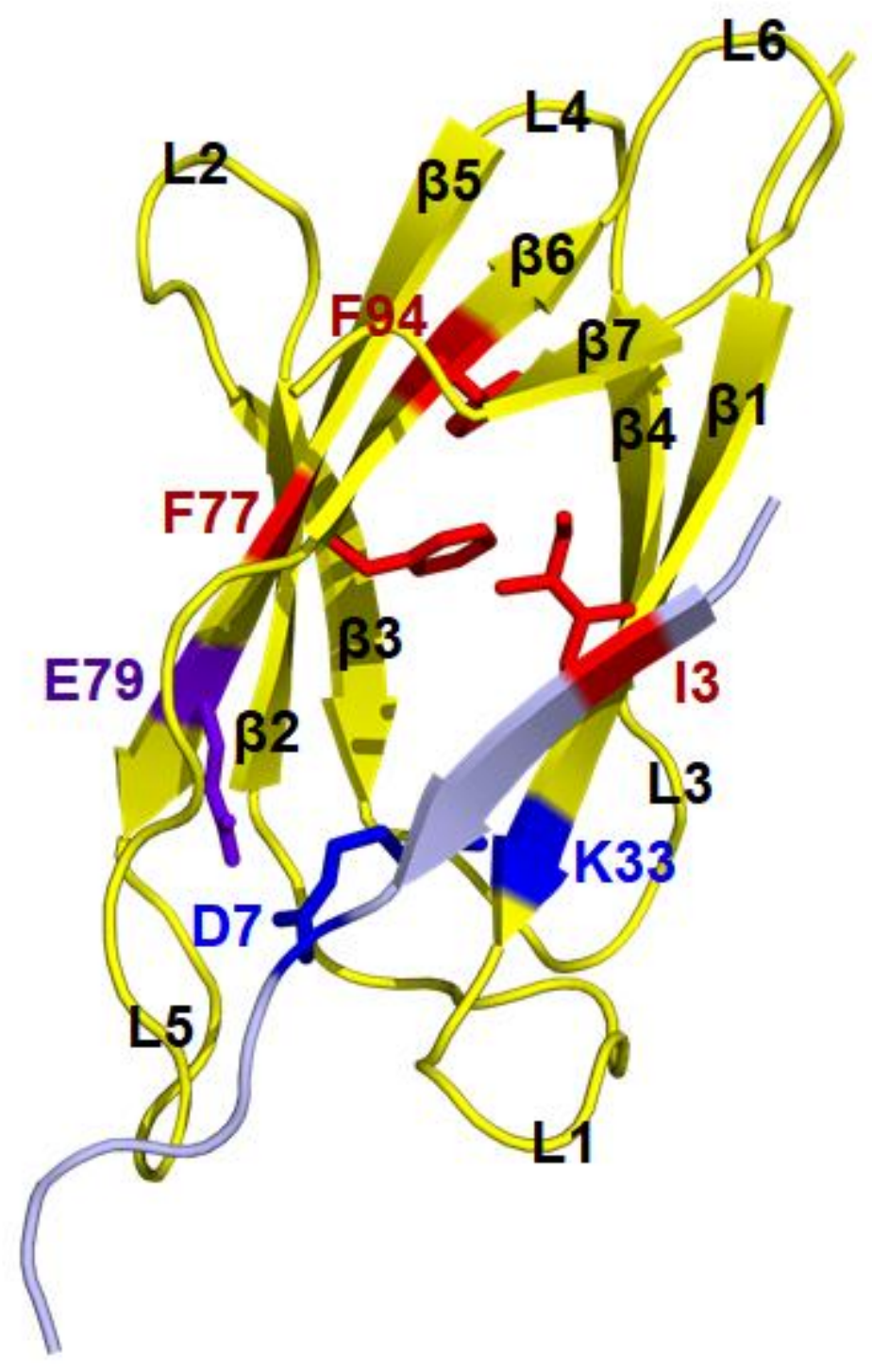

Figure S1. Secondary structure assignment of the SpyTag-SpyCatcher complex (PDB Entry: 4MLI). The key hydrophobic residues involved in the study are labeled red (I3 on SpyTag, F94 and F77 on SpyCatcher). The catalytic glutamic acid (E79 on SpyCatcher) is labeled purple. The reactive lysine (K33 on SpyCatcher) and aspartic acid (D7 on SpyTag) are labeled blue. 

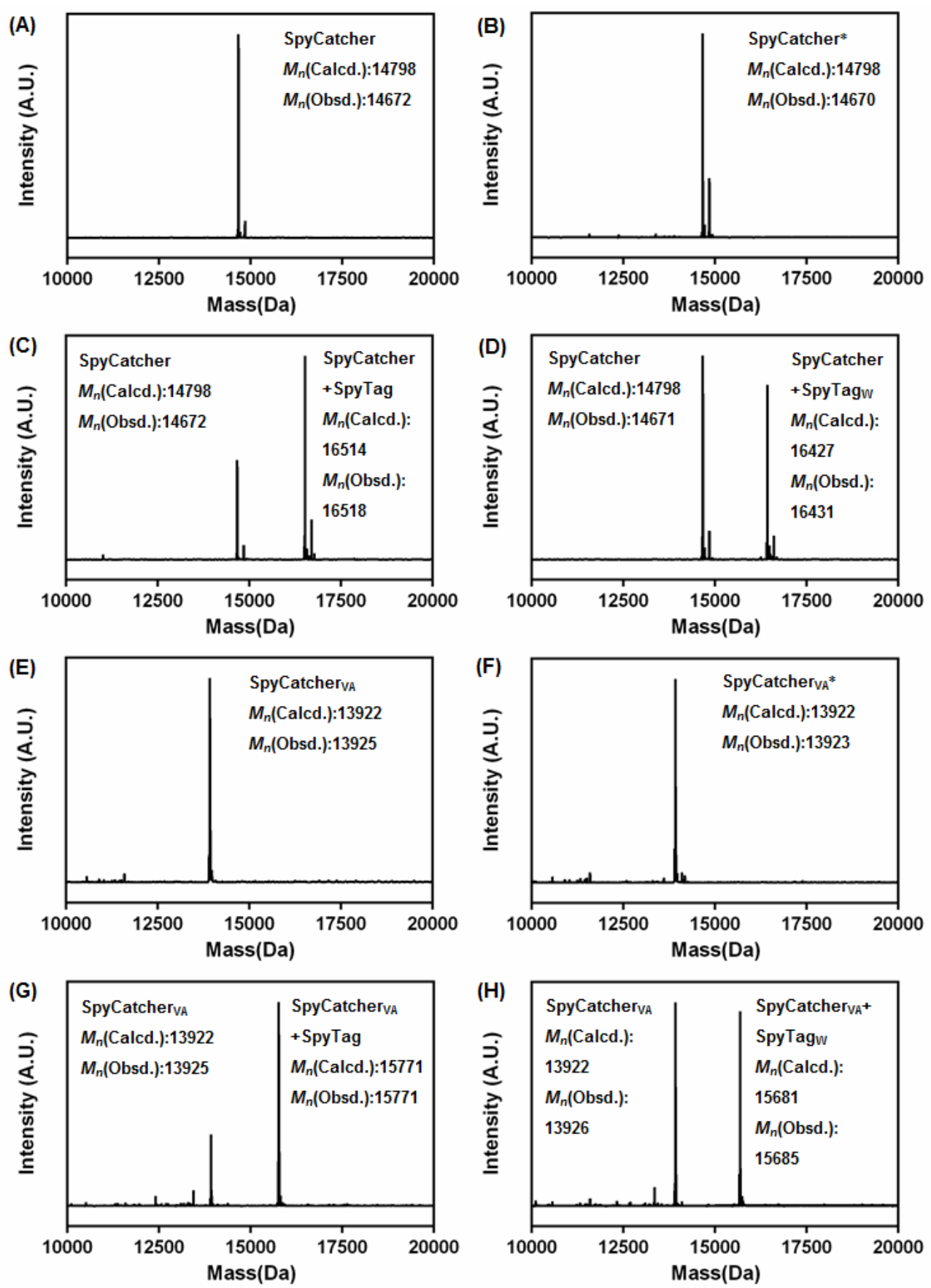

Figure S2. LC-MS spectra of the SpyCatcher (A), SpyCatcher* (B), the SpyTag-SpyCatcher complex (C), the SpyTagw-SpyCatcher complex (D), SpyCatcherva (E), SpyCatchervA* (F), the SpyTagSpyCatcherva complex (G), and the SpyTagw-SpyCatcherva complex (H). For SpyCatcher and SpyCatcher*, the -128 Da modification is caused by the removal of N-terminal fMet. The peak of the unconjugated SpyCatcher and the covalent product are labeled separately. The SpyTag used here has the sequence of AHIVMVDAYKPTKGSGSC and the SpyTagw mutant has the sequence of AHWVMVDAYKPTKGSS. 


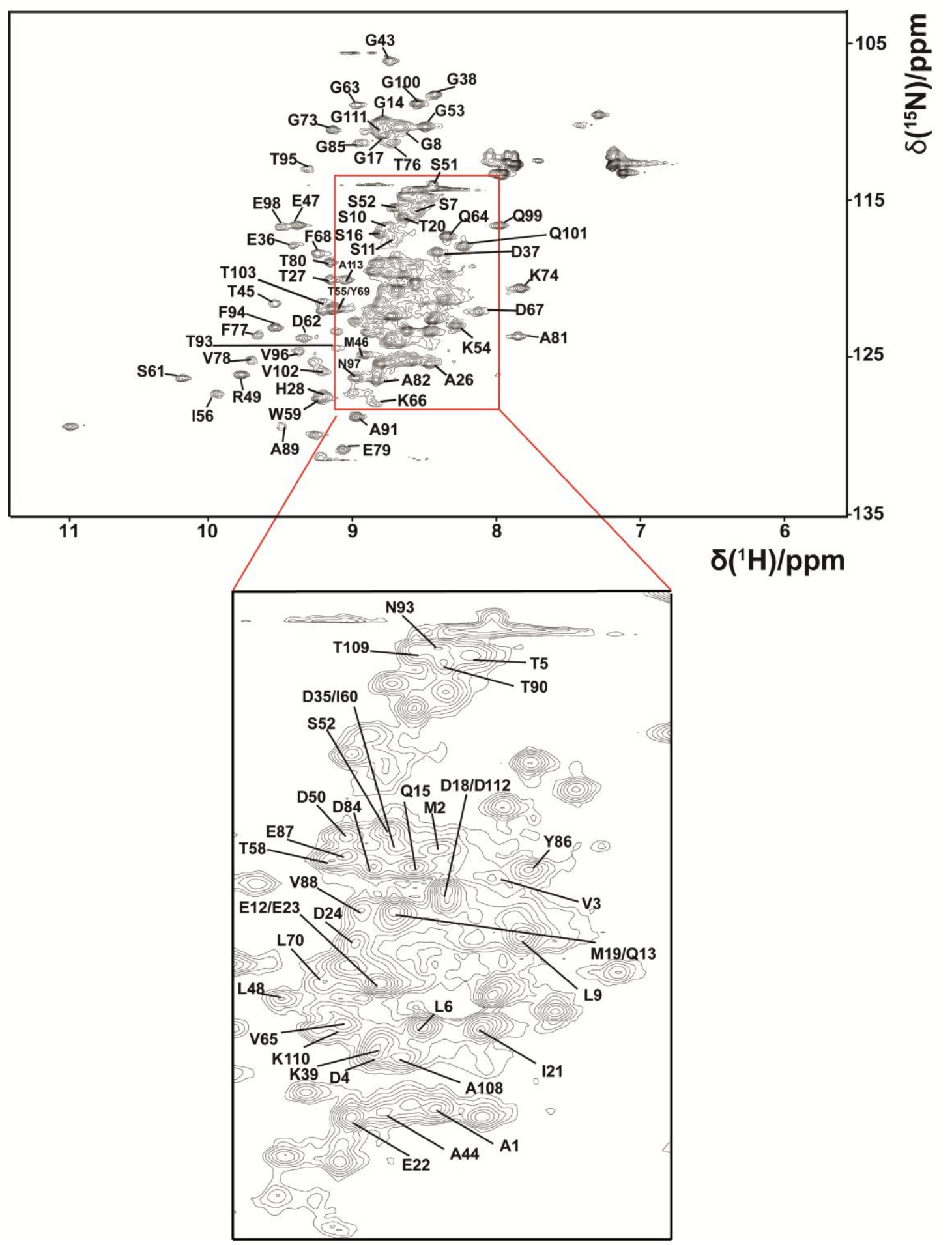

Figure S3. ${ }^{1} \mathrm{H}_{-}{ }^{15} \mathrm{~N}$ HSQC spectrum of SpyCatcher at $15{ }^{\circ} \mathrm{C}$ with assignments. 

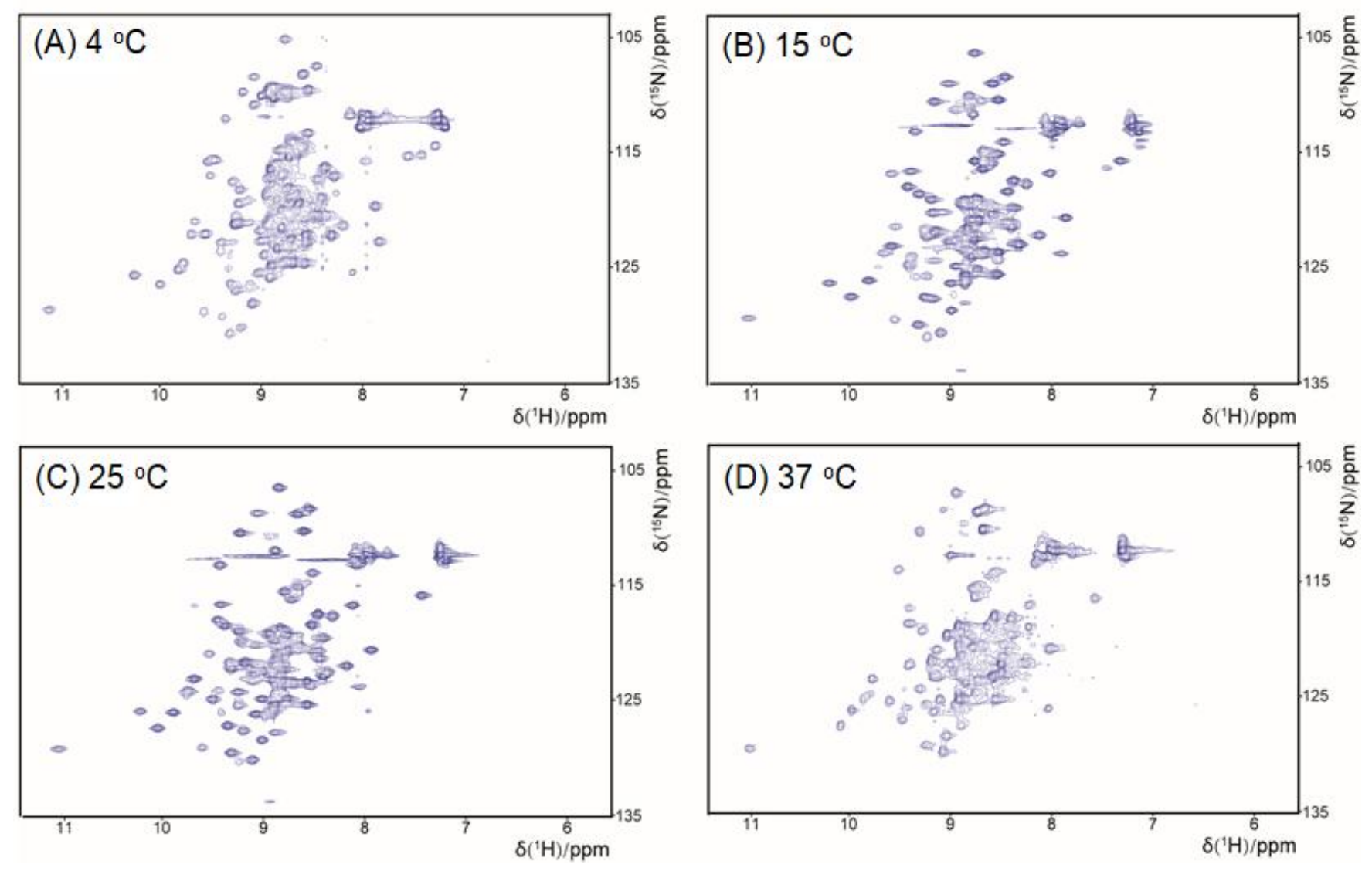

Figure S4. ${ }^{1} \mathrm{H}-{ }^{15} \mathrm{~N}$ HSQC spectra of SpyCatcher at different temperatures: (A) $4{ }^{\circ} \mathrm{C}$, (B) $15{ }^{\circ} \mathrm{C},(\mathrm{C}) 25{ }^{\circ} \mathrm{C}$, (D) $37^{\circ} \mathrm{C}$. 


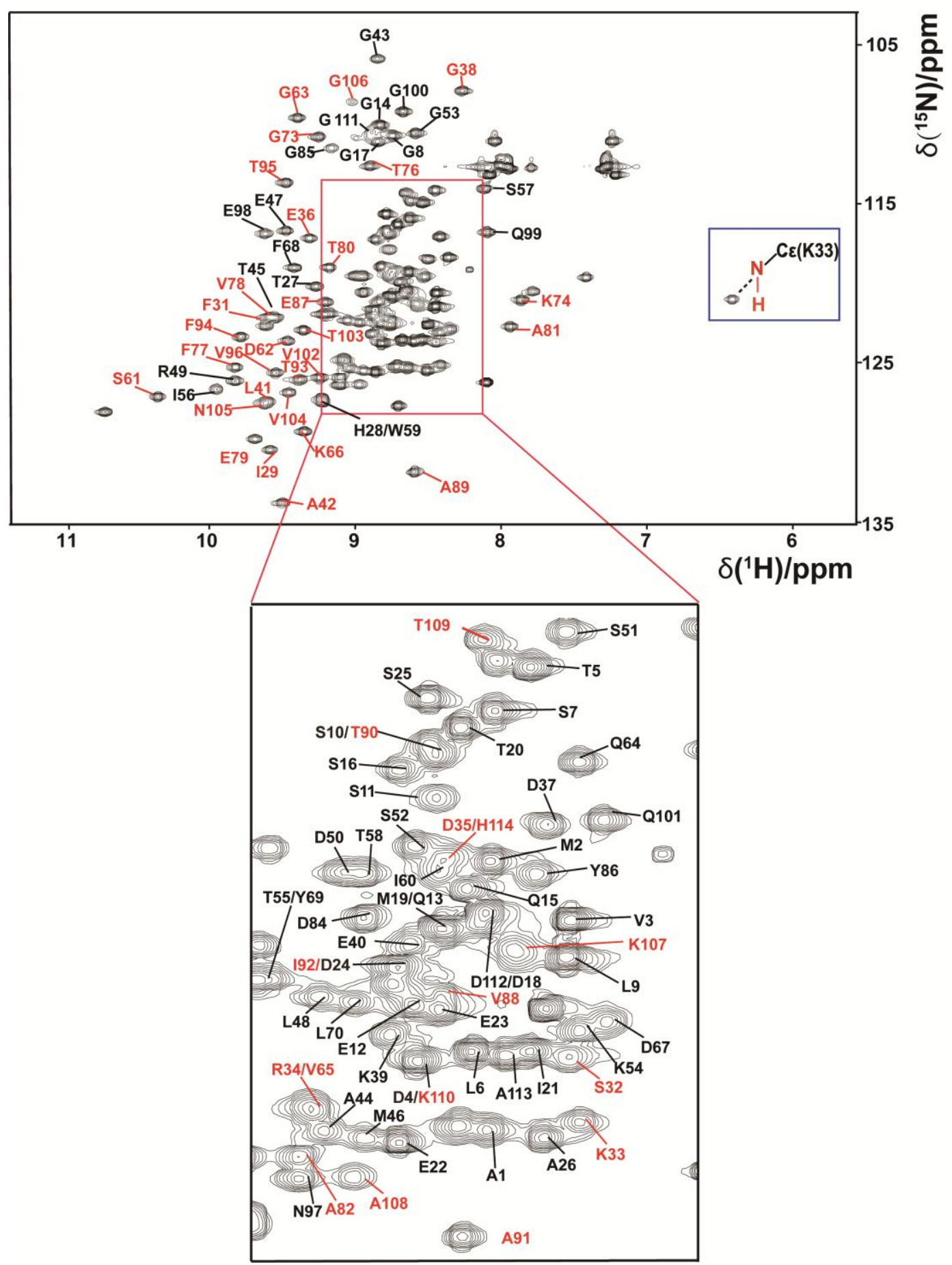

Figure S5. ${ }^{1} \mathrm{H}_{-}{ }^{15} \mathrm{~N}$ HSQC spectrum of SpyCatcher in SpyTag-SpyCatcher complex at $15{ }^{\circ} \mathrm{C}$ with assignments. The residues labeled in red have a large chemical shift difference or are missing in the assignment of the free SpyCatcher. 

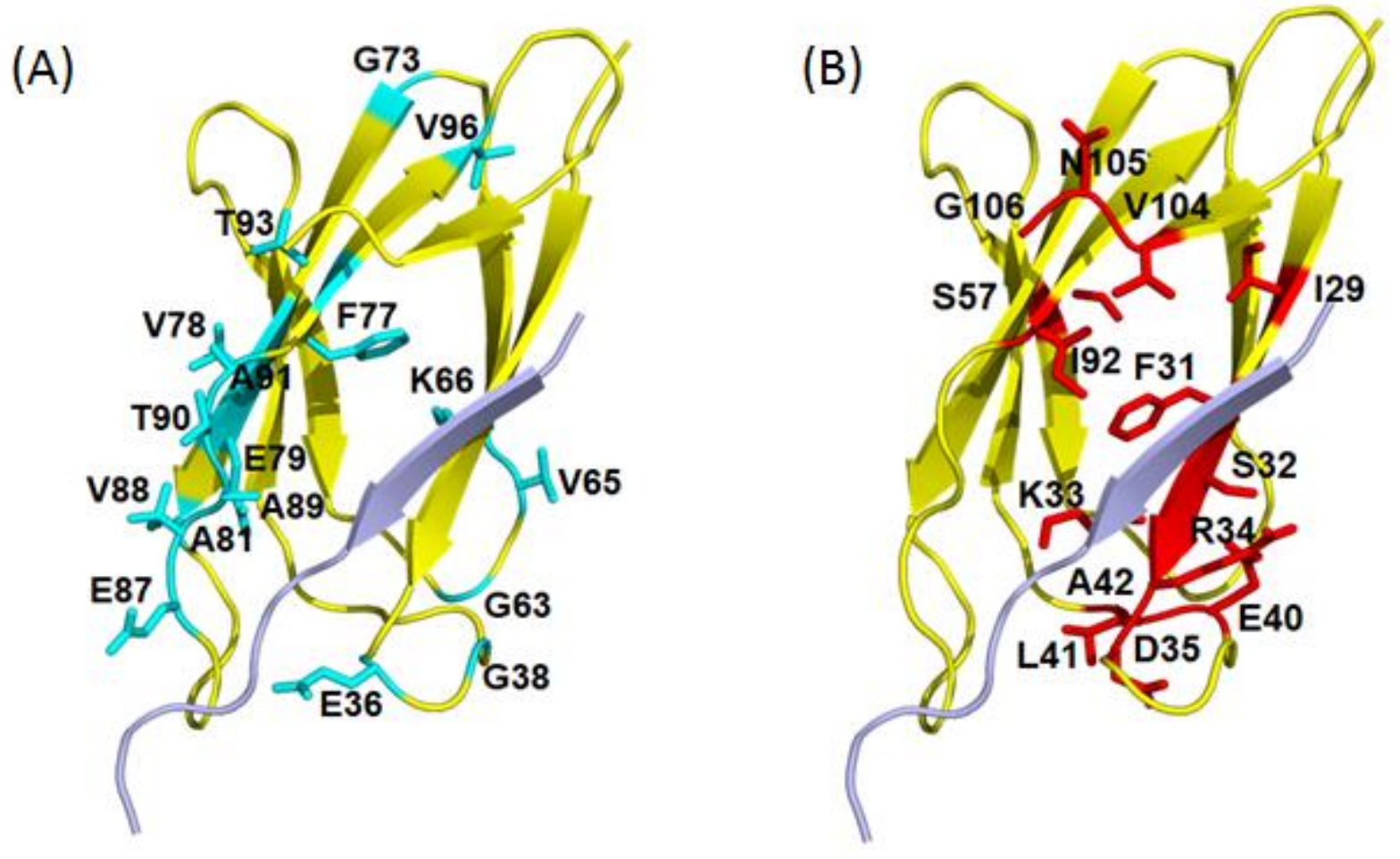

Figure S6. Mapping of residues onto the crystal structure: (A) residues showing large CSV during SpyTag-SpyCatcher binding labeled in cyan; (B) residues specifically found in the SpyTag-SpyCatcher complex labeled in red. 

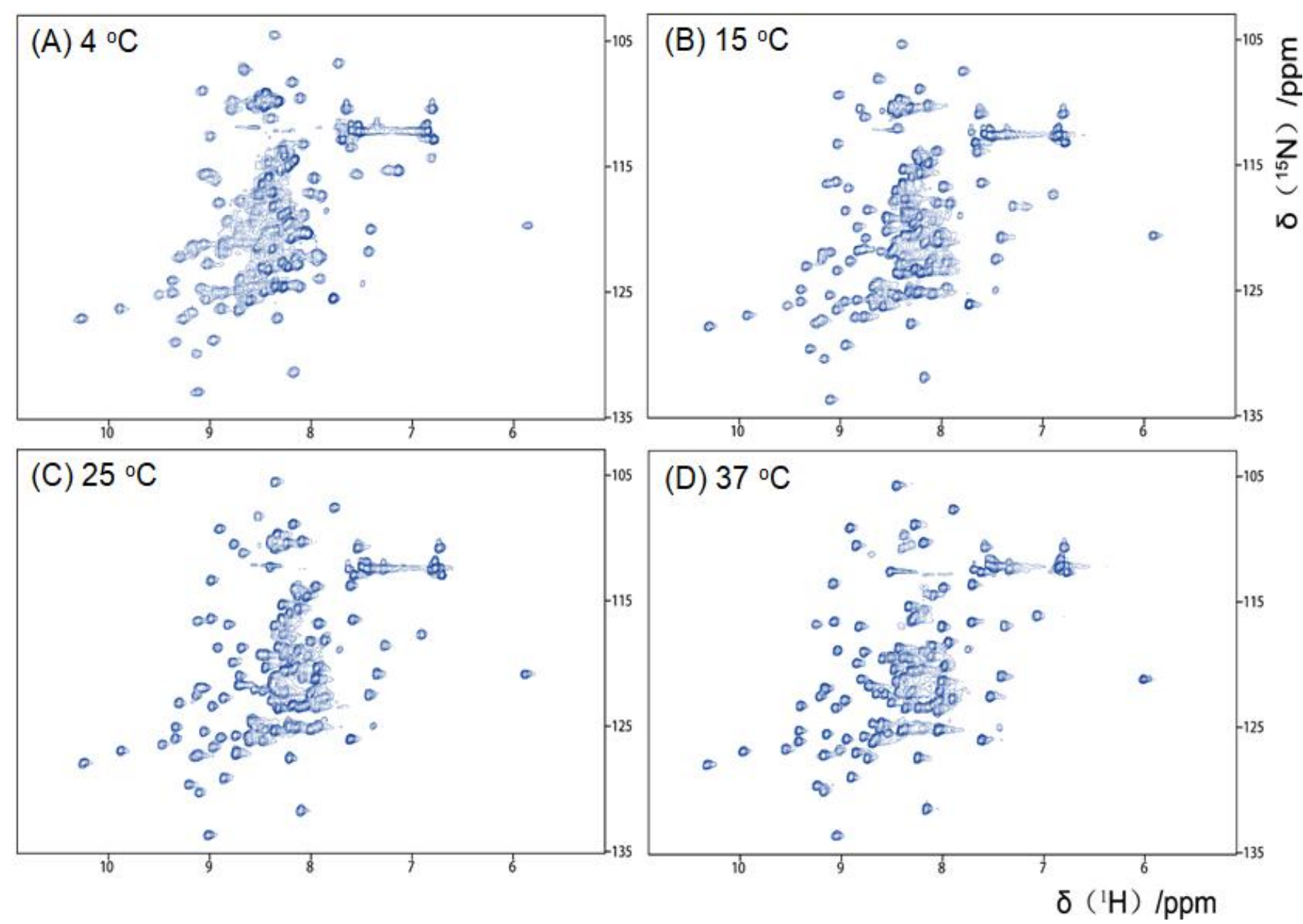

Figure S7. ${ }^{1} \mathrm{H}_{-}{ }^{15} \mathrm{~N}$ HSQC spectra of SpyCatcher in the SpyTag-SpyCatcher complex at different temperatures: (A) $4{ }^{\circ} \mathrm{C}$, (B) $15^{\circ} \mathrm{C}$, (C) $25^{\circ} \mathrm{C}$, (D) $37^{\circ} \mathrm{C}$. 


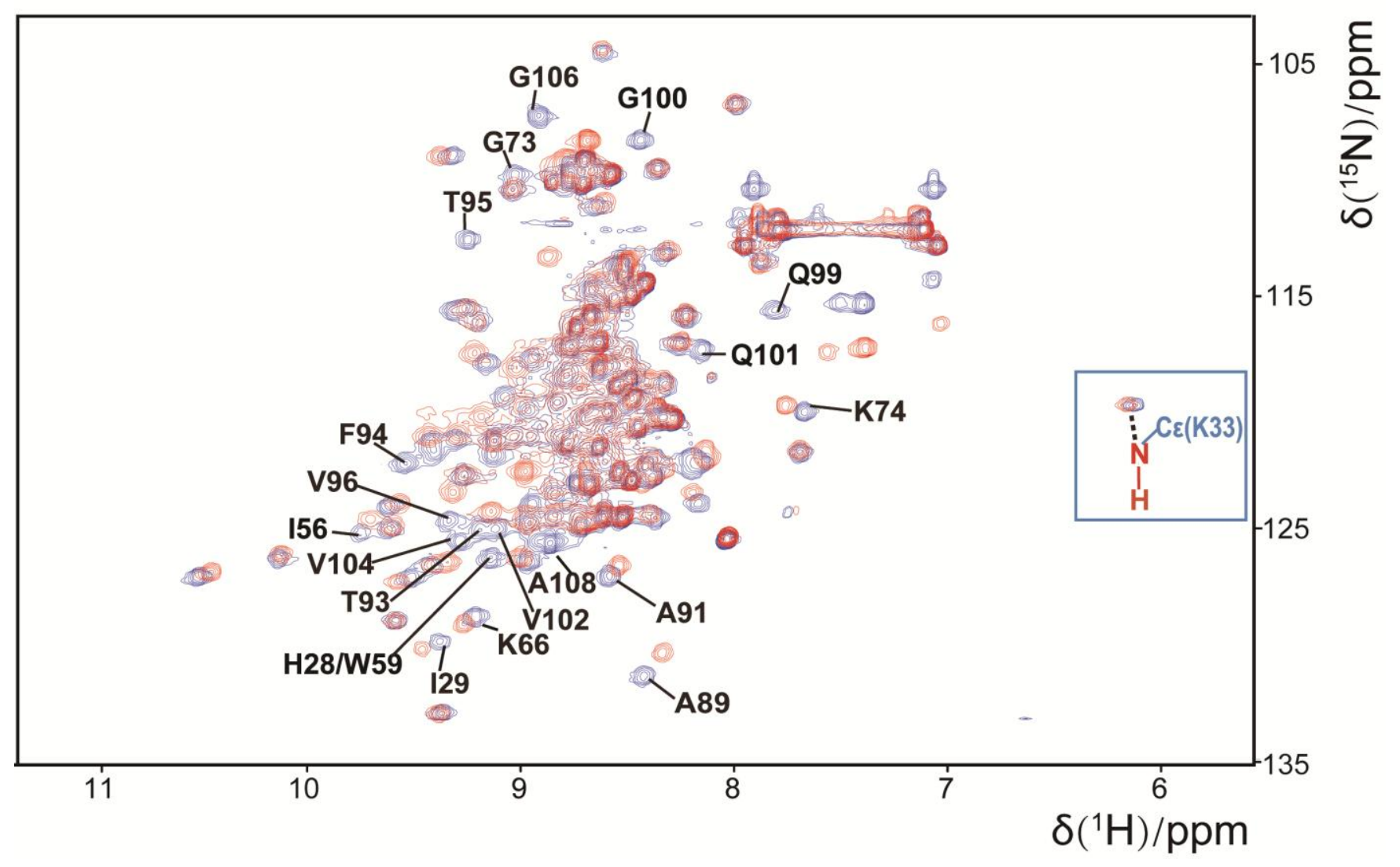

Figure S8. Overlay of ${ }^{1} \mathrm{H}_{-}{ }^{15} \mathrm{~N}$ HSQC spectra of the SpyTag-SpyCatcher complex (blue) with SpyTag $\mathrm{Y}^{-}$ SpyCatcher complex (red). The residues with large shift in cross peaks in SpyTag-SpyCatcher complex

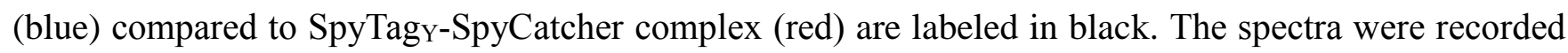
at $4{ }^{\circ} \mathrm{C}$. 


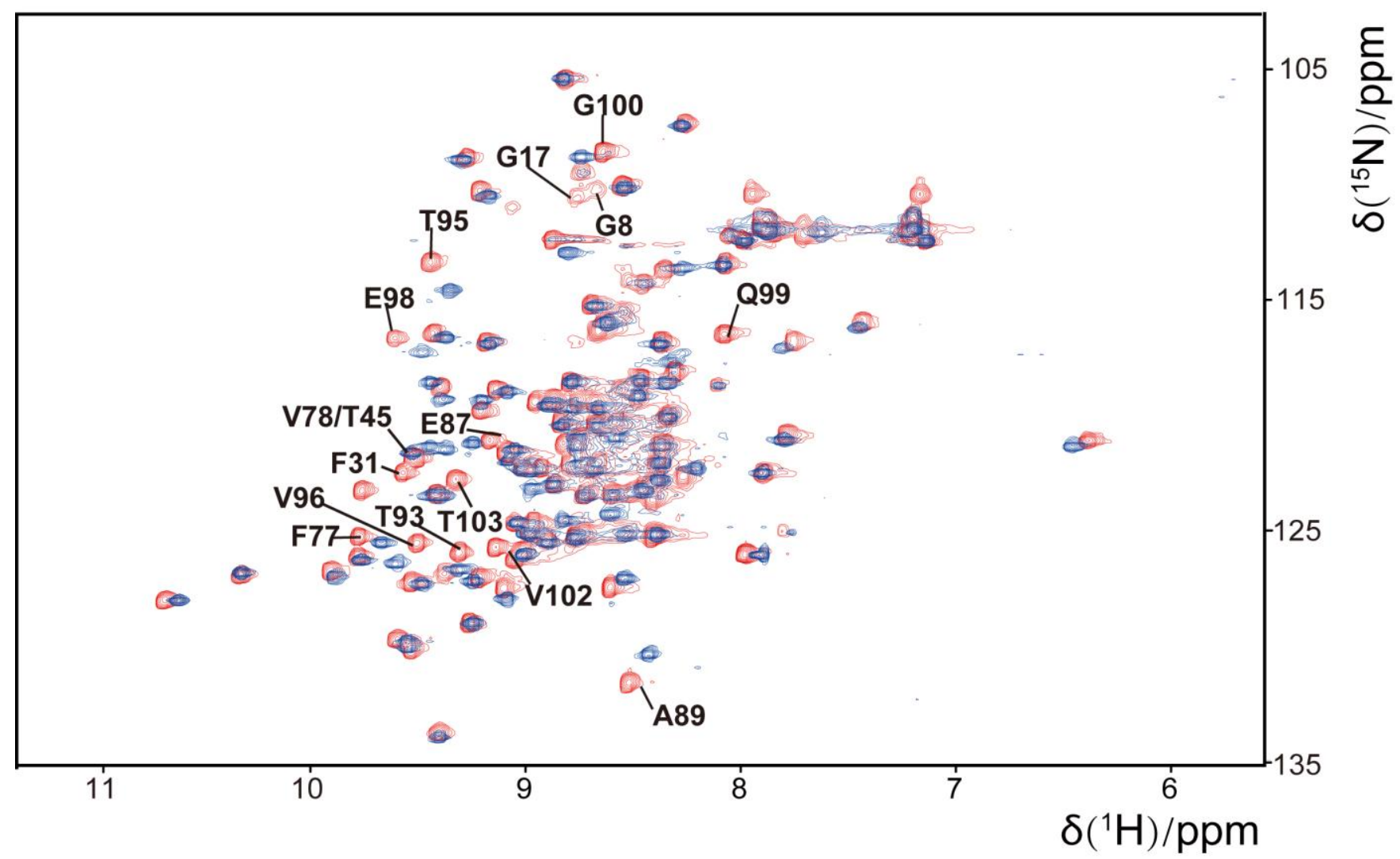

Figure S9. Overlay of ${ }^{1} \mathrm{H}_{-}{ }^{15} \mathrm{~N}$ HSQC spectra of the SpyTag-SpyCatcher complex (red) and the SpyTagwSpyCatcher complex (blue) after $12 \mathrm{~h}$ of incubation at $37^{\circ} \mathrm{C}$. The residues with large shift in cross peaks in the SpyTag-SpyCatcher complex (red) compared to SpyTagw-SpyCatcher complex (blue) are labeled in black. The spectra were recorded at $37^{\circ} \mathrm{C}$. 


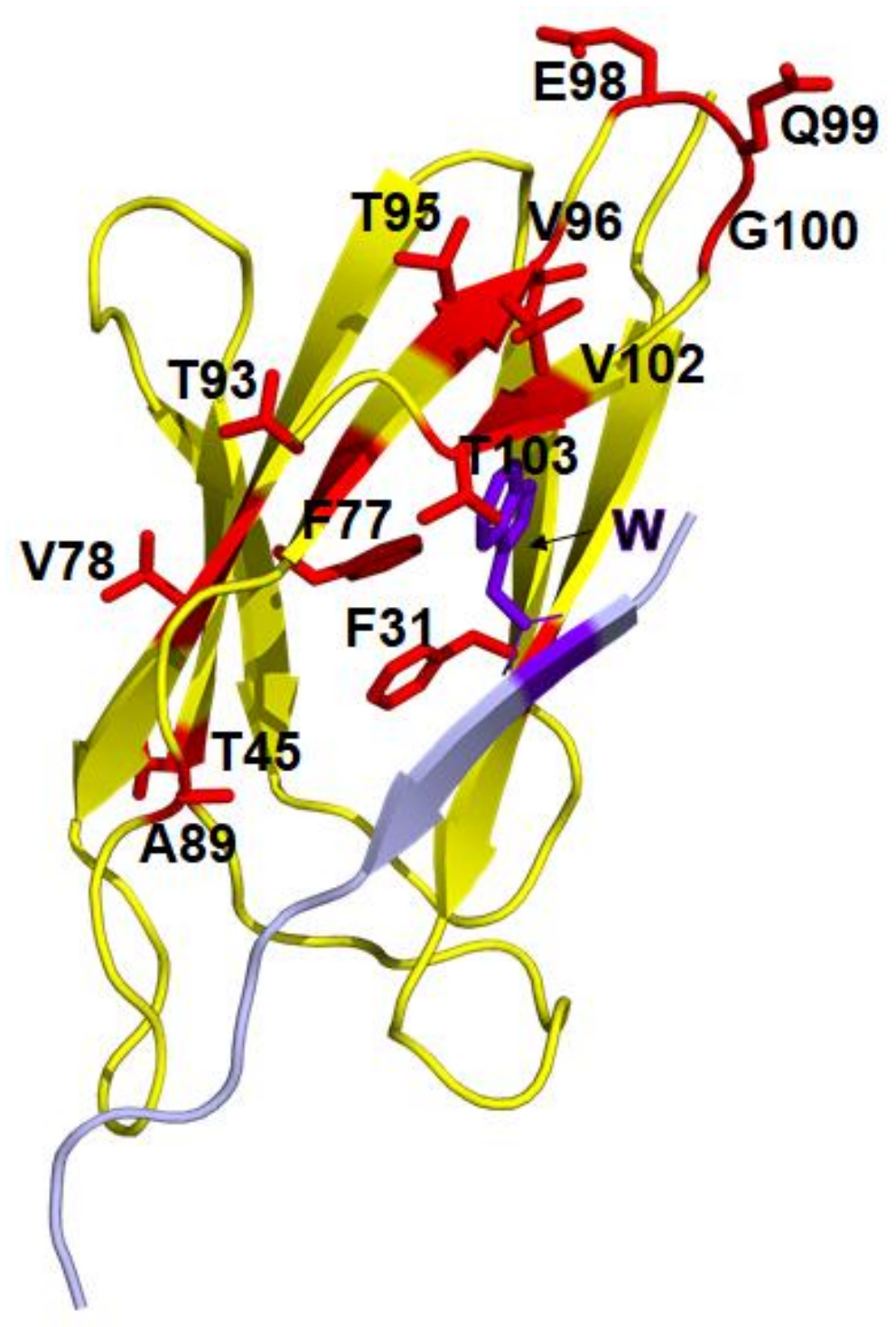

Figure S10. Mapping of residues showing large peak shift in the SpyTagw-SpyCatcher covalent complex relative to the SpyTag-SpyCatcher complex to the crystal structure of the SpyTag-SpyCatcher complex. 


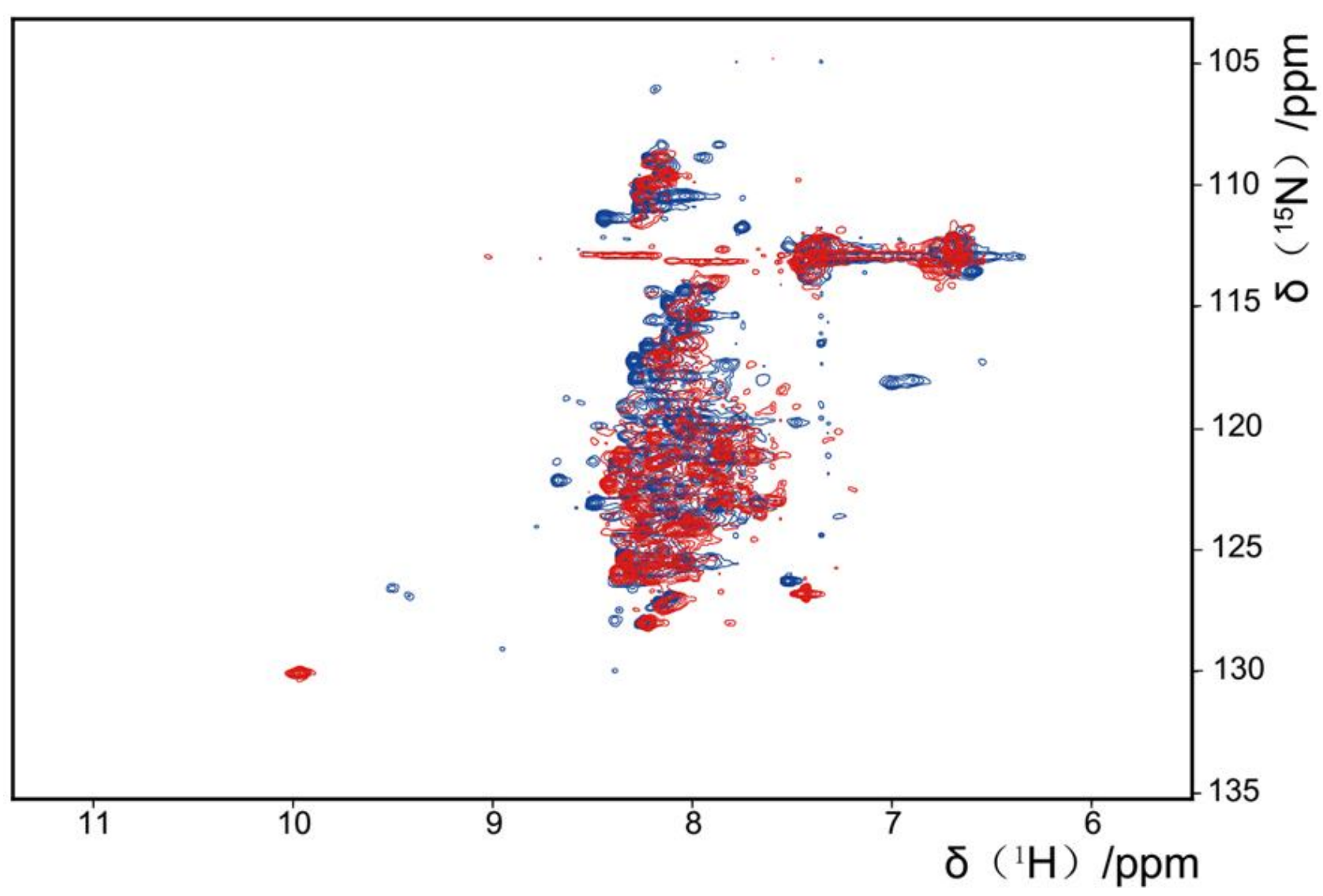

Figure S11. Overlay of ${ }^{1} \mathrm{H}-{ }^{15} \mathrm{~N}$ HSQC spectra of SpyCatcher ${ }_{V A}$ at $4{ }^{\circ} \mathrm{C}$ (blue) and $37{ }^{\circ} \mathrm{C}$ (red). 


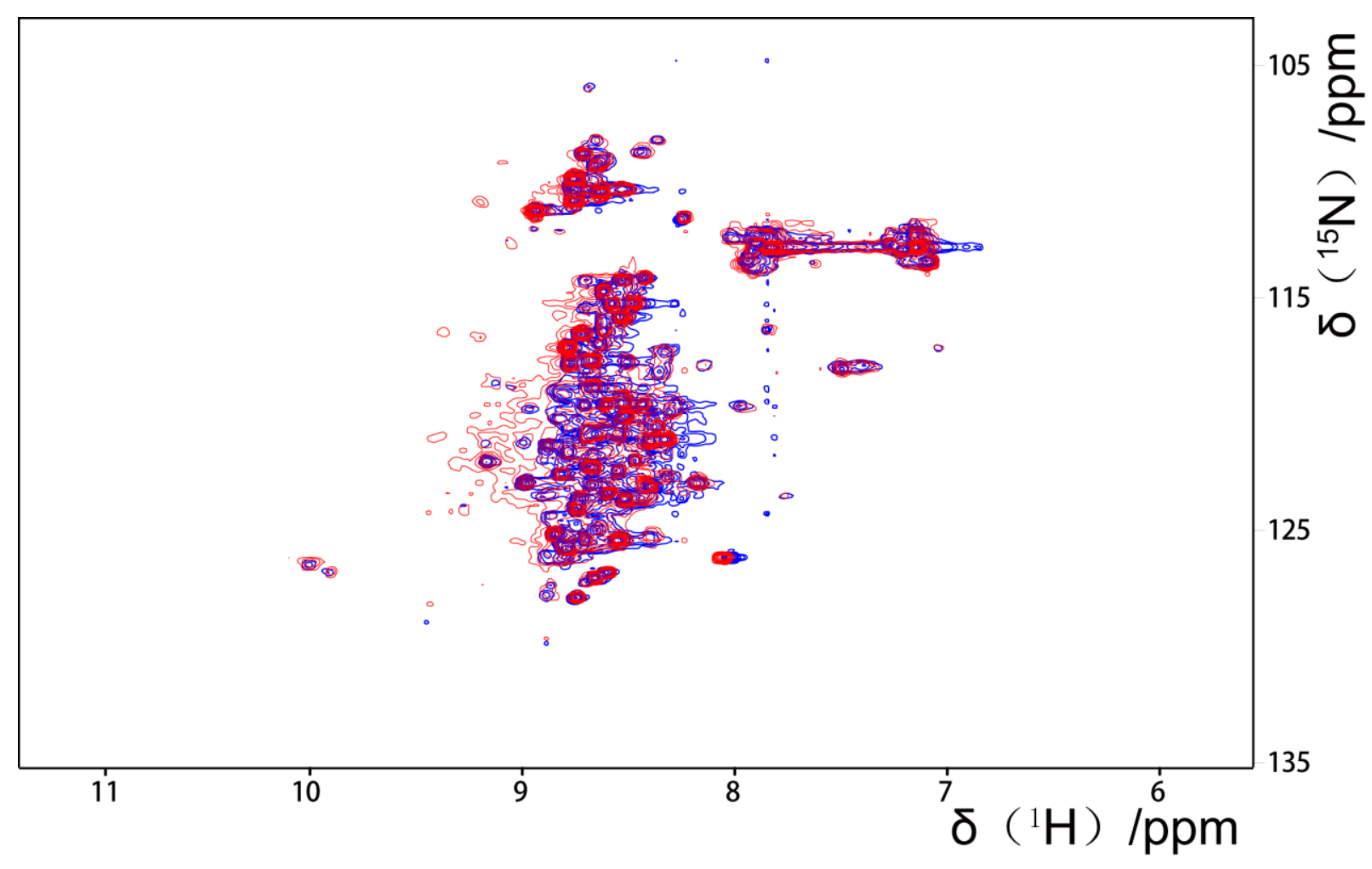

Figure S12. Overlay of ${ }^{1} \mathrm{H}_{-}{ }^{15} \mathrm{~N}$ HSQC spectra of SpyCatcher ${ }_{\mathrm{VA}}$ (blue) and the mixture of SpyTag and SpyCatcher $_{V A}$ (red). The spectra were recorded at $4{ }^{\circ} \mathrm{C}$. 
(A)

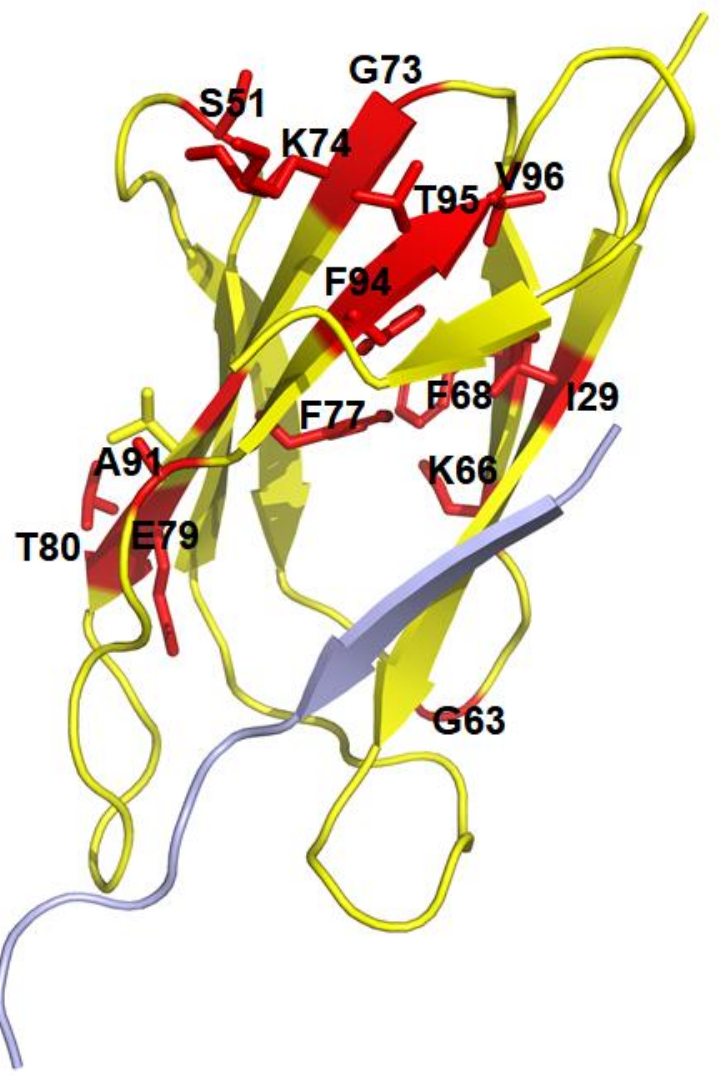

(B)

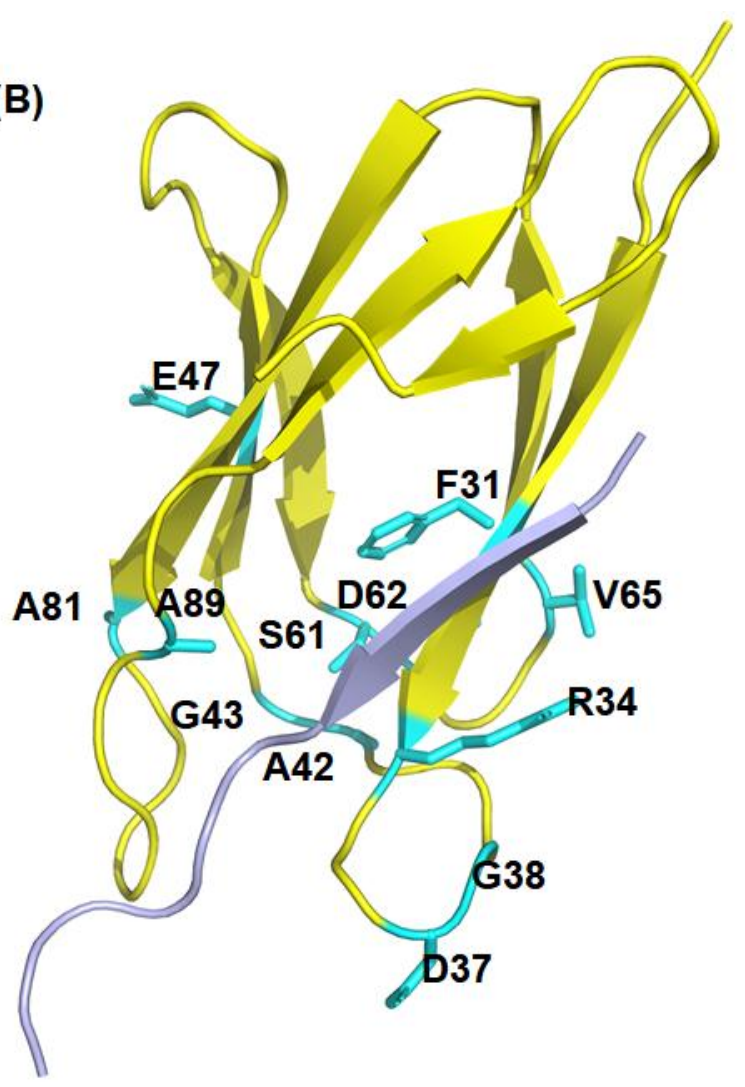

Figure S13. Mapping of residues (A) showing large peak shift and (B) showing unchanged peaks in the SpyTag-SpyCatcherva complex relative to the SpyTag-SpyCatcher complex. It shows that the changed residues (A, red) are predominantly located in the region $\beta 5-\beta 6$ critical in the formation of the hydrophobic core and the unchanged residues (B, cyan) are mainly located in the region L1 and L3 close to the isopeptide bond. 


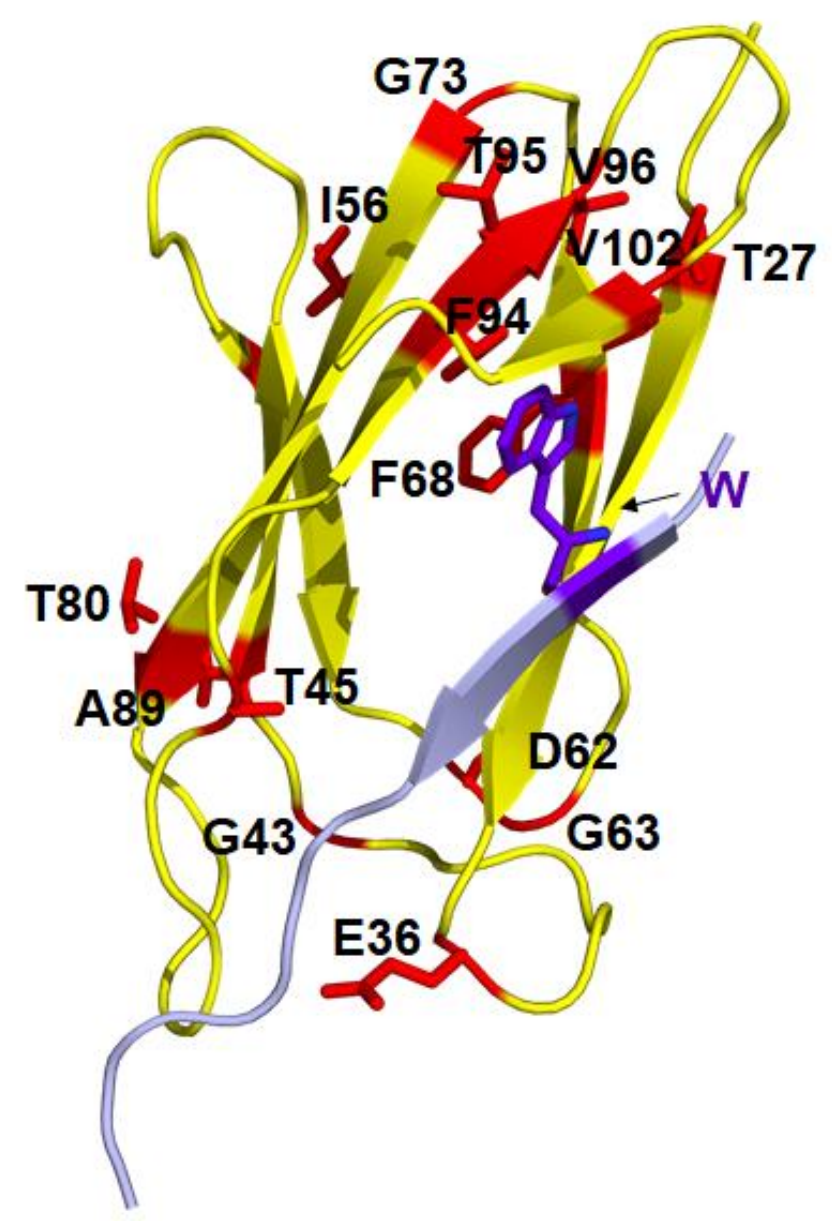

Figure S14. Mapping of residues showing large peak shift in SpyTag ${ }_{W}-$ SpyCatcher physical complex relative to SpyCatcher to the crystal structure of the SpyTag-SpyCatcher complex, which reflects the dynamic segments at the interaction interface. 


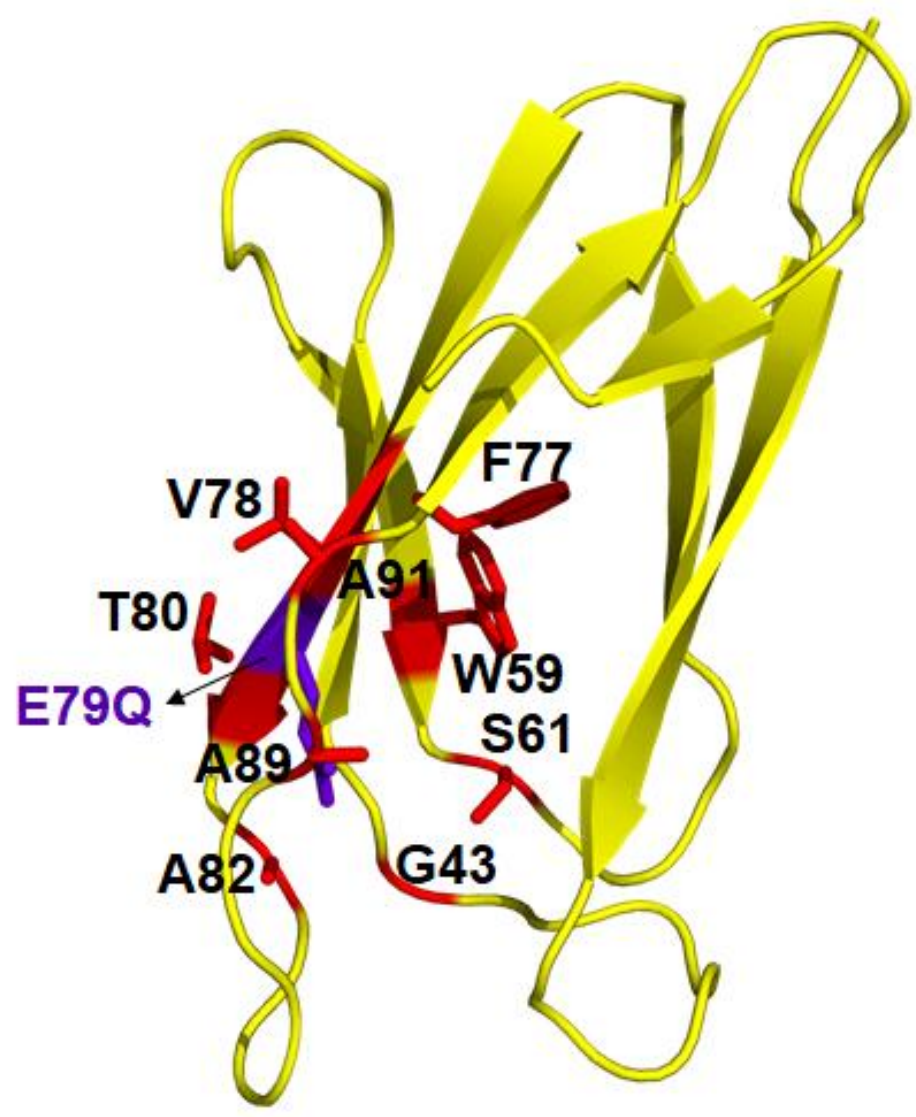

Figure S15. Mapping of residues showing large peak shifts in SpyCatcher* as compared to SpyCatcher. The mutated catalytic site (Q79) is labeled purple. Most changes occur on the residues spatially close to Q79. 


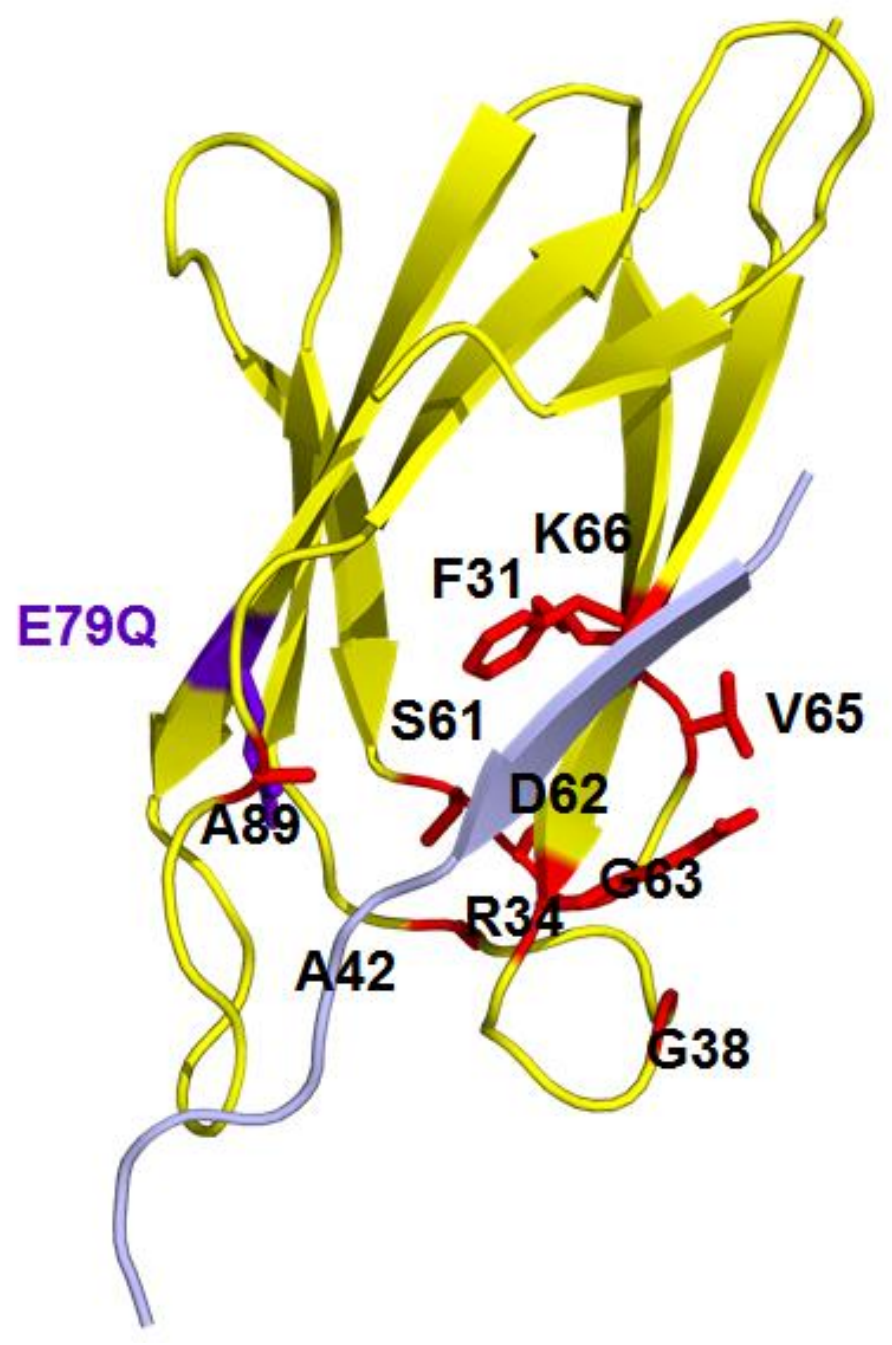

Figure S16. Mapping of residues showing broadening or large peak shift in the SpyTag-SpyCatcher complex relative to SpyTag-SpyCatcher* to the crystal structure of the SpyTag-SpyCatcher complex. This reflects the structural change after binding upon the covalent bond formation. 